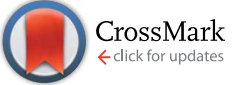

Cite this: RSC Adv., 2014, 4, 61383
Received 15th September 2014 Accepted 6th November 2014

DOI: $10.1039 / \mathrm{c} 4 \mathrm{ra10476e}$

www.rsc.org/advances

\section{Triptycene based organosoluble polyamides: synthesis, characterization and study of the effect of chain flexibility on morphology $\dagger$}

\author{
Snehasish Mondal and Neeladri Das*
}

Synthesis of new triptycene-containing polyamides (TPAs) using 2,6-diaminotriptycene and various aromatic and aliphatic dicarboxylates (Yamazaki-Higashi phosphorylation polyamidation) is described. The effect of the polymer backbone flexibility on the surface morphology of the respective polymer is studied. Polyamides thus prepared are organosoluble and have relatively low solution viscosities $(0.18-$ $0.5 \mathrm{dL} \mathrm{g}^{-1}$ ). TGA indicated that triptycene polyamides containing aliphatic chains are thermally less stable than the wholly aromatic triptycene polyamides. These polyamides may be categorized as selfextinguishing materials. FTIR spectroscopy studies show that hydrogen bonding interactions are weaker in wholly aromatic polyamides (TPA1-TPA3) relative to those in semi-aromatic polyamides (TPA4-TPA6). FE-SEM images of TPAs show that replacement of aromatic dicarboxylates with aliphatic dicarboxylates results in a drastic change in the morphology of the polyamides.

\section{Introduction}

Polyamides are one of the most important and versatile classes of synthetic polymers known to date..$^{1-7}$ Monomeric building blocks in polyamides can be either wholly aromatic (also known as aramides, e.g., Kevlar ${ }^{\circledR}$, Nomex®) ${ }^{5-7}$ semi-aromatic (a combination of both aromatic and aliphatic monomers, e.g., Torgamide $\mathrm{T} \circledast$, Amodel $\left.{ }^{8}\right)^{8-10}$ and purely aliphatic (e.g., Nylon $\left.{ }^{\circledR}\right) .^{7,11,12}$ Polyamides have attracted research attention because of their high thermal stabilities, excellent mechanical properties and inherent chemical resistance..$^{5,13-16}$ These properties are often attributed to inter-molecular hydrogen bonds $(\mathrm{CO} \cdots \mathrm{HN})$ that strengthen interchain interactions. ${ }^{17}$ Applications of polyamides are manifold, which include material for products such as cords, ropes, fiber for garments (for daily use as well as for special use such as firefighting/military applications), hoses, and insulating jackets on electrical wires, sports equipment, and sheath for optical fibers. Aramides are also being used as "space age" materials for manufacturing goods that are employed for outer-space

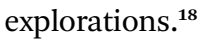

This justifies importance of polyamides as synthetic polymers and their use as materials for use in advanced technologies. In this context, it must be mentioned that while aramides are thermally more stable than the purely aliphatic polyamides (Nylons), the former suffer from the disadvantage of poor solubility (due to intrinsic macromolecular inflexibility,

Department of Chemistry, Indian Institute of Technology Patna, Patna 800 013, Bihar, India.E-mail: neeladri@iitp.ac.in; neeladri2002@yahoo.co.in; Tel: +916122552023 † Electronic supplementary information (ESI) available. See DOI: 10.1039/c4ra10476e stronger interchain interactions, or semicrystallinity). ${ }^{\mathbf{1 3 , 1 9 - 2 1}}$ This restricts the processability and also limits applications of aramides to some extent. However, in the past few decades, there have been several approaches to improve the low solubility of wholly aromatic polyamides. This includes introduction of bulky groups (in the polymer backbone or as pendant groups in main chain) ${ }^{\mathbf{1 3 , 2 2 - 3 3}}$ that disrupt packing and/or incorporation of flexible spacer (usually alkyl units) in the polymer backbone. ${ }^{34-39}$ These modifications in polymer design decrease inter-molecular hydrogen bonds ( $\mathrm{CO} \cdots \mathrm{HN})$, weaken inter-chain interactions and consequently improve solubility of the resulting polymer.

Triptycene, first synthesized by Bartlett and coworkers in 1942, is the simplest member of iptycene family. ${ }^{40}$ Triptycene has a rigid three dimensional (3D) structure with a paddle wheel configuration of three benzene rings that are connected together by a [2.2.2] bicyclic bridge. Triptycene based polymers were first reported by Klanderman and Faber in $1968 .{ }^{41}$ Over the past fifteen years, Swager, Chen and others have extensively explored triptycene chemistry. ${ }^{\mathbf{4 2 - 5 7}}$ More recently, there is lot of excitement in polymer synthesis with the incorporation of triptycene in the polymer backbone or as a bulky pendent group in the main chain. ${ }^{\mathbf{5 8 , 5 9}}$ Swager and coworkers have established that incorporation of triptycene building blocks in polymer chains enhances solubility and imparts high thermal stability. The rigid three dimensional paddle wheel structure of triptycene generates "internal free volume", which in turn is responsible for the resulting interesting properties associated with polymers containing triptycene derivatives as monomeric units. ${ }^{47}$ 
However, to the best of our knowledge, there are only two literature reports of polyamides prepared from triptycene derived monomers. In the first example, Kasashima et al. utilized 1,5-disubstituted triptycene diamine as a monomer, ${ }^{60}$ while in the second report, Hsiao et al. have employed 1,4disubstituted triptycene derivatives as polymer building blocks. ${ }^{58}$ On comparing the aforementioned two sets of triptycene polyamides, it is obvious that the orientation of the triptycene is different in the resulting polymer chains, since the relative position of the two functional groups on triptycene core is different.

It is known that on one hand strong interchain interactions (efficient packing of polymer chains) exist in polyamides, and on the other hand triptycene disrupts packing efficiency of polymer chains. It is reported that polyurethanes (PUs) containing triptycene motif have lesser extent of $\mathrm{H}$-bonding relative to nontriptycene PUs. ${ }^{59}$ Considering the importance of polyamides in general and triptycene based polymers in particular, we were interested to design triptycene based polyamides. The objective is to study effect of flexibility of the polymer backbone on the morphological properties of the resultant polymer. Continuing our research efforts aimed at exploring newer applications of triptycene derivatives, ${ }^{\mathbf{6 1 , 6 2}}$ herein we describe the syntheses of new series of alternating polyamides (wholly aromatic as well as semi-aromatic) using 2,6-diaminotriptycene as one of the monomeric building blocks, via Yamazaki-Higashi phosphorylation polyamidation reaction. ${ }^{\mathbf{6 3 , 6 4}}$ Polymers were characterized by spectroscopic techniques (NMR and FTIR), gel permeation chromatography (GPC), thermal analysis (TGA and DSC), and powder X-ray diffraction (PXRD) techniques. Hydrogen bonding interactions in these polyamides were examined using FTIR spectroscopy. Field emission scanning electron microscope (FE-SEM) was used to study the changes in surface morphologies of the polyamides due to incorporation of aromatic or aliphatic dicarboxylate motifs in the polymer backbone.

\section{Experimental}

\section{Materials}

All chemicals were purchased from Sigma-Aldrich or Alfa Aesar. Pyridine was dried in laboratory applying a common technique. Anhydrous NMP was purchased from Sigma-Aldrich.

\section{General methods and Instrumentation}

NMR spectra were obtained using Bruker Avance II 400 Spectrometer. FTIR spectra were measured using PerkinElmer Spectrum-400 spectrometer. Molecular weight of each polymer was estimated using Agilent PL-GPC 50 integrated GPC spectrometer [using polystyrene standard and DMF (with $0.5 \% \mathrm{LiBr}$ as additive) as an eluent at a flow rate $1.0 \mathrm{~mL} \mathrm{~min}^{-1}$ at $45^{\circ} \mathrm{C}$ ]. Viscosity of each polymer solution in DMF $\left(0.5 \mathrm{~g} \mathrm{dL}^{-1}\right.$ concentration at $25{ }^{\circ} \mathrm{C}$ ) was measured using BrookField DV-II + Pro Viscometer. UV-vis spectra were obtained using Shimadzu UV2550 UV-vis spectrophotometer. TGA analyses were performed using SDT Q600 (TA Instruments) under nitrogen atmosphere at a scan rate $10{ }^{\circ} \mathrm{C} \mathrm{min}^{-1}$. DSC analyses were carried out using DSC8000 (PerkinElmer) under nitrogen at a scan rate $10{ }^{\circ} \mathrm{C}$ $\min ^{-1}$. PXRD data were obtained using Rigaku TTRAX III X-ray diffractometer. Melting points were measured using SRS EZ-Melt automated melting point apparatus. FE-SEM images were obtained using Hitachi S-4800 Field Emission Scanning Electron Microscope.

\section{General synthesis of polymer}

In a two neck round bottom flask containing 2,6-diaminotriptycene (142 mg, $0.5 \mathrm{mmol}$ ), corresponding dicarboxylic acid (0.5 mmol), $\mathrm{CaCl}_{2}$ (55 mg, $0.5 \mathrm{mmol}$ ) and $\mathrm{LiCl}(22 \mathrm{mg}, 0.5 \mathrm{mmol})$ were added. The round bottom flask was connected with a reflux condenser while maintaining inert atmosphere. Then NMP ( $1 \mathrm{~mL})$, pyridine $(0.25 \mathrm{~mL})$ and triphenyl phosphite (TPP, $0.5 \mathrm{~mL}, 1.9 \mathrm{mmol}$ ) were added to the reaction mixture with a syringe. The reaction mixture was stirred at $110^{\circ} \mathrm{C}$. After $5 \mathrm{~h}$, the viscous solution was cooled to room temperature and poured in methanol $(100 \mathrm{~mL})$. A fibrous precipitate was formed upon vigorous stirring. The precipitate was filtered off and washed with hot water and methanol. The residue was dried under vacuum at $100{ }^{\circ} \mathrm{C}$ to obtain the desired polyamide (TPA) as a white powder in excellent yield.

TPA1. Yield: $185 \mathrm{mg}, 98 \% ; M_{\mathrm{n}}=25.3 \mathrm{kDa}$; PDI $=1.23 ;{ }^{1} \mathrm{H}$ NMR: $\delta_{\mathrm{H}}\left(400 \mathrm{MHz}\right.$; DMSO-d $\left.{ }_{6} ; \mathrm{Me}_{4} \mathrm{Si}\right) 10.25$ (s, 2H; NH), 7.908.20 (m, 6H, Ar H), 7.20-7.60 (m, 6H, Ar H), 6.90-7.10 (m, 2H, Ar $\mathrm{H}), 5.57$ (s, 2H; CH); FTIR (KBr): $\nu_{\max } / \mathrm{cm}^{-1} 1535$ (vs; amide II), $1599\left(\mathrm{~m} ; \nu_{\mathrm{C}=\mathrm{O}}\right.$ (amide I (H-bonded))), 1657 (m; $\nu_{\mathrm{C}=\mathrm{O}}$ (amide I (non H-bonded))), 3285 (wb; $\nu_{\mathrm{s}}(\mathrm{N}-\mathrm{H})$ ).

TPA2. Yield: $183 \mathrm{mg}, 97 \% ; M_{\mathrm{n}}=26.6 \mathrm{kDa}$ PDI $=1.19 ;{ }^{1} \mathrm{H}$ NMR: $\delta_{\mathrm{H}}\left(400 \mathrm{MHz} ; \mathrm{DMSO}-\mathrm{d}_{6} ; \mathrm{Me}_{4} \mathrm{Si}\right) 10.30-10.34(\mathrm{~m}, 2 \mathrm{H}), 8.40-$ $8.60(\mathrm{~m}, 1 \mathrm{H}), 8.05-8.20(\mathrm{~m}, 2 \mathrm{H}), 7.90-8.05(\mathrm{~m}, 2 \mathrm{H}), 7.55-7.70$ (m, 1H), 7.25-7.55 (m, 6H), 6.90-7.10 (m, 2H), 5.59 (s, 2H); FTIR (KBr): $\nu_{\max } / \mathrm{cm}^{-1} 1533$ (vs; amide II), 1600 (m; $\nu_{\mathrm{C}=\mathrm{O}}$ (amide I (H-bonded))), 1657 (vs; $\nu_{\mathrm{C}=\mathrm{O}}$ (amide I (non H-bonded))), 3286 $\left(\mathrm{wb} ; \nu_{\mathrm{s}}(\mathrm{N}-\mathrm{H})\right)$.

TPA3. Yield: $211 \mathrm{mg}, 99 \% ; M_{\mathrm{n}}=33 \mathrm{kDa}$; PDI $=1.35$; ${ }^{1} \mathrm{H}$ NMR: $\delta_{\mathrm{H}}\left(400 \mathrm{MHz} ; \mathrm{DMSO}-\mathrm{d}_{6} ; \mathrm{Me}_{4} \mathrm{Si}\right)$ 10.30-10.50 (m, 2H), 8.50-8.70 (m, 2H), 7.90-8.30 (m, 6H), 7.20-7.60 (m, 6H), 6.90$7.20(\mathrm{~m}, 2 \mathrm{H}), 5.61(\mathrm{~s}, 2 \mathrm{H})$; FTIR $(\mathrm{KBr}): \nu_{\max } / \mathrm{cm}^{-1} 1531$ (vs; amide II), $1598\left(\mathrm{~m} ; \nu_{\mathrm{C}=\mathrm{O}}\right.$ (amide I (H-bonded)) $1652\left(\mathrm{vs} ; \nu_{\mathrm{C}=\mathrm{O}}\right.$ (amide I (non H-bonded))), $3280\left(\mathrm{wb} ; \nu_{\mathrm{s}}(\mathrm{N}-\mathrm{H})\right)$.

TPA4. Yield: $168 \mathrm{mg}, 94 \% ; M_{\mathrm{n}}=25.5 \mathrm{kDa}$; PDI $=1.29$; ${ }^{1} \mathrm{H}$ NMR: $\delta_{\mathrm{H}}\left(400 \mathrm{MHz} ;\right.$ DMSO-d $\left.{ }_{6} ; \mathrm{Me}_{4} \mathrm{Si}\right)$ 9.65-9.80 (m, 2H), 7.70-7.85 (m, 2H), 7.32-7.45 (m, 2H), 7.18-7.32 (m, 2H), 7.02$7.12(\mathrm{~m}, 2 \mathrm{H}), 6.90-7.02(\mathrm{~m}, 2 \mathrm{H}), 5.42(\mathrm{~s}, 2 \mathrm{H}), 2.15-2.40(\mathrm{~m}, 4 \mathrm{H})$, 1.50-1.75 (m, 4H); FTIR (KBr): $\nu_{\max } / \mathrm{cm}^{-1} 1537$ (vs; amide II), $1599\left(\mathrm{~m} ; \nu_{\mathrm{C}=\mathrm{O}}\right.$ (amide I (H-bonded))), 1662 (vs; $\nu_{\mathrm{C}=\mathrm{O}}$ (amide I (non H-bonded))), 2955 (w), 3292 (wb; $\left.\nu_{\mathrm{s}}(\mathrm{N}-\mathrm{H})\right)$.

TPA5. Yield: $202 \mathrm{mg}, 98 \% ; M_{\mathrm{n}}=24 \mathrm{kDa}$; PDI $=1.23 ;{ }^{1} \mathrm{H}$ NMR: $\delta_{\mathrm{H}}\left(400 \mathrm{MHz}\right.$; DMSO-d ${ }_{6}$; $\left.\mathrm{Me}_{4} \mathrm{Si}\right)$ 9.60-9.80 (m, 2H), 7.34$7.43(\mathrm{~m}, 2 \mathrm{H}), 7.25-7.32(\mathrm{~m}, 2 \mathrm{H}), 7.02-7.11$ (m, 2H), 6.90-7.00 (m, 2H), 5.45 (s, 2H), 2.15-2.3 (m, 2H), 1.45-1.70 (m, 2H), 1.101.45 (m, 4H); FTIR (KBr): $\nu_{\max } / \mathrm{cm}^{-1} 1536$ (vs; amide II), 1599 (m; $\nu_{\mathrm{C}=\mathrm{O}}$ (amide I (H-bonded)), 1663 (vs; $\nu_{\mathrm{C}=\mathrm{O}}$ (amide I (non H-bonded))), 2854 (w), 2926 (w), 3302 (wb; $\nu_{\mathrm{s}}(\mathrm{N}-\mathrm{H})$ ). 
TPA6. Yield: $196 \mathrm{mg}, 89 \% ; M_{\mathrm{n}}=26.2 \mathrm{kDa}$; PDI $=1.26 ;{ }^{1} \mathrm{H}$ NMR: $\delta_{\mathrm{H}}\left(400 \mathrm{MHz} ; \mathrm{DMSO}_{6} \mathrm{~d}_{6} ; \mathrm{Me}_{4} \mathrm{Si}\right) 9.65$ (s, 2H), 7.31-7.44 $(\mathrm{m}, 2 \mathrm{H}), 7.22-7.31(\mathrm{~m}, 2 \mathrm{H}), 7.02-7.12(\mathrm{~m}, 2 \mathrm{H}), 6.90-7.01$ (m, $2 \mathrm{H}), 5.40(\mathrm{~s}, 2 \mathrm{H}), 2.15-2.3(\mathrm{~m}, 2 \mathrm{H}), 1.48-1.67(\mathrm{~m}, 2 \mathrm{H}), 1.25$ (s, broad, 6H); FTIR (KBr): $\nu_{\max } / \mathrm{cm}^{-1} 1535$ (vs; amide II), 1599 $\left(\mathrm{m} ; \nu_{\mathrm{C}=\mathrm{O}}\right.$ (amide I (H-bonded))), 1662 (vs; $\nu_{\mathrm{C}=\mathrm{O}}$ (amide I (non H-bonded))), 2851 (w), 2924 (w), 3292 (wb; $\nu_{\mathrm{s}}(\mathrm{N}-\mathrm{H})$ ).

\section{Results and discussion}

\section{Synthesis of monomer}

2,6-Dinitrotriptycene (DNT) was prepared from triptycene based on synthetic protocol described by Swager and coworkers. ${ }^{65}$ Reduction of DNT thus obtained using hydrazine hydrate and Raney Nickel (in $\mathrm{MeOH}$ as solvent) resulted in the quantitative formation of the desired monomer 2,6-diaminotriptycene (DAT) (Scheme 1). The ${ }^{1} \mathrm{H}$ NMR spectrum of the product obtained indicated the formation of pure 2,6-diaminotriptycene (ESI $\dagger$ ). High purity DAT thus obtained was in turn utilized to prepare triptycene based polyamides described herein. Both DNT and DAT were characterized (NMR and melting point) and the data is in agreement with that reported in literature. ${ }^{65}$

\section{Synthesis of polyamides}

The Yamazaki-Higashi phosphorylation polyamidation reaction was utilized for synthesis of triptycene based polymers reported herein. This method has several advantages such as facile and efficient synthesis (high yield involving minimal number of steps) of polyamide and diversity in substrate scope. Employing 2,6-diaminotriptycene (DAT) and various aromatic and aliphatic dicarboxylic acids, two sets of polyamides have been synthesized [wholly aromatic polyamides (TPA1-TPA3) and semi-aromatic polyamides (TPA4-TPA6)] (Scheme 2). The reactions were carried out using 1-methyl-2-pyrrolidone (NMP) as solvent. The viscous solutions obtained by stirring each reaction mixture at $110^{\circ} \mathrm{C}$ for $5 \mathrm{~h}$ were quenched in $\mathrm{MeOH}$ with vigorous stirring to yield fibrous precipitates in nearly quantitative yields. The molecular weight of each polyamide was determined by gel permeation chromatography (GPC) using polystyrene as a standard and DMF (containing $0.5 \% \mathrm{LiBr}$ as additive) as an eluent. The number average molecular weight $\left(M_{\mathrm{n}}\right)$ obtained for TPA1-TPA6 was found to vary in the range 24 $\mathrm{kDa}$ to $33 \mathrm{kDa}$. In case of TPA4 and TPA5, the respective GPC traces indicate multimodal nature that may be due to phase separation during polymerization process leading to the formation of oligomeric species as well. The corresponding polydispersity index (PDI) (see ESI $\dagger$ ) and degree of polymerization $\left(P_{\mathrm{n}}\right)$ varied from 1.19-1.35 and 54-71 respectively (Table 1).
Comparison with PDI of previously reported triptycene based polyamides (see ESI $\dagger$ ) suggests a relatively narrower molecular weight distribution in case of TPAs. The inherent viscosity of the polymer in DMF (at a concentration of $0.5 \mathrm{~g} \mathrm{dL}^{-1}$ ) was found to vary from 0.18 to $0.51 \mathrm{dL} \mathrm{g}^{-1}$ (Table 1 ). Comparison of properties of the polyamides reported herein with those reported previously in literature has been summarized in ESI. $\dagger$ TPAs reported herein have relatively lower inherent viscosities than other triptycene based polyamides reported in literature. These low inherent viscosities may be explained in terms of reduction of interchain interaction due to presence of rigid threedimensional triptycene unit in polymer backbone. ${ }^{65}$

\section{Spectroscopic characterization of polymer}

The proton NMR spectrum in each case (Fig. 1 and ESI $\dagger$ ) suggested polycondensation between 2,6-DAT and the respective dicarboxylic acid. Representative proton NMR spectrum of a wholly aromatic polyamide (TPA3) and a semi-aromatic polyamide (TPA6) are shown in Fig. 1. In the ${ }^{1} \mathrm{H}$ NMR spectrum of TPA3, the singlet at $5.61 \mathrm{ppm}$ is assigned to bridgehead proton of triptycene $\left(\mathrm{H}_{\mathrm{f}}\right)$. The multiplet in the range $\delta=10.30-10.50$ ppm corresponds to the amide proton. The signal centered at $\delta=7.02 \mathrm{ppm}$ corresponds to the $\mathrm{H}_{\mathrm{a}}$ proton of triptycene. Signals due to $\mathrm{H}_{\mathrm{b}}, \mathrm{H}_{\mathrm{d}}$ and $\mathrm{H}_{\mathrm{e}}$ proton of triptycene appear as multiplet in the range $\delta=7.20-7.60 \mathrm{ppm}$. The peaks due to the protons of naphthalene moiety appear in the range $\delta=7.90-$ $8.30 \mathrm{ppm}\left(\mathrm{H}_{\mathrm{i}}\right.$ and $\left.\mathrm{H}_{\mathrm{j}}\right)$ and at $\delta=8.60\left(\mathrm{H}_{\mathrm{k}}\right)$. As expected, the integration ratio of all signals in the range $\delta=6.90-8.70 \mathrm{ppm}$ and that due to the bridgehead protons of triptycene $\left(\mathrm{H}_{\mathrm{f}}\right)$ is approximately $8: 1$. Similarly ${ }^{1} \mathrm{H}$ NMR spectrum of the semiaromatic polyamide TPA6 is consistent with the expected repeating unit structure. The singlet at $\delta=5.40 \mathrm{ppm}$ corresponds to bridge head proton of triptycene $\left(\mathrm{H}_{\mathrm{f}}\right)$. Five signals in the aromatic region correspond to the five chemically inequivalent peaks of triptycene moiety. Incorporation of the bridging aliphatic dicarboxylate in the polyamide is obvious from the signals in the range $\delta=1.20-2.30 \mathrm{ppm}$. The integration ratio of aromatic protons in the range $\delta=6.95-7.79 \mathrm{ppm}$ and aliphatic protons in the range $\delta=1.20-2.30 \mathrm{ppm}$ is equal to $1: 2$ as expected. Insets in Fig. 1 show detailed peak assignments for polyamide TPA6. In general, for all the triptycene polyamides being reported herein, the characteristic bridgehead protons of the triptycene unit appears in the region $\delta=5.4-5.6 \mathrm{ppm}$ while the amide protons appear in between $\delta=9.70-10.35$ (see ESI $\dagger$ ) with integration ratio $1: 1$. Thus proton NMR spectral assignments in case of each polymer agree well the proposed polymer structures.

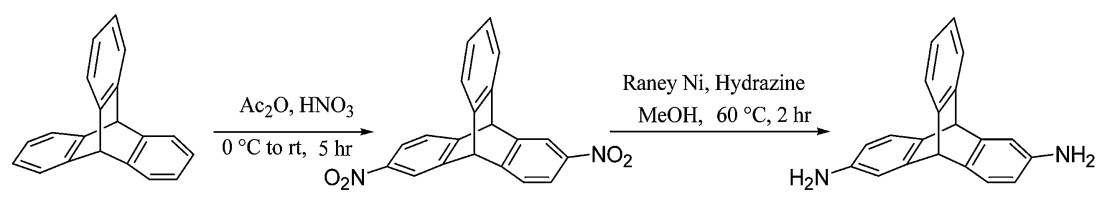

Scheme 1 Synthesis of 2,6-diaminotriptycene (DAT). 


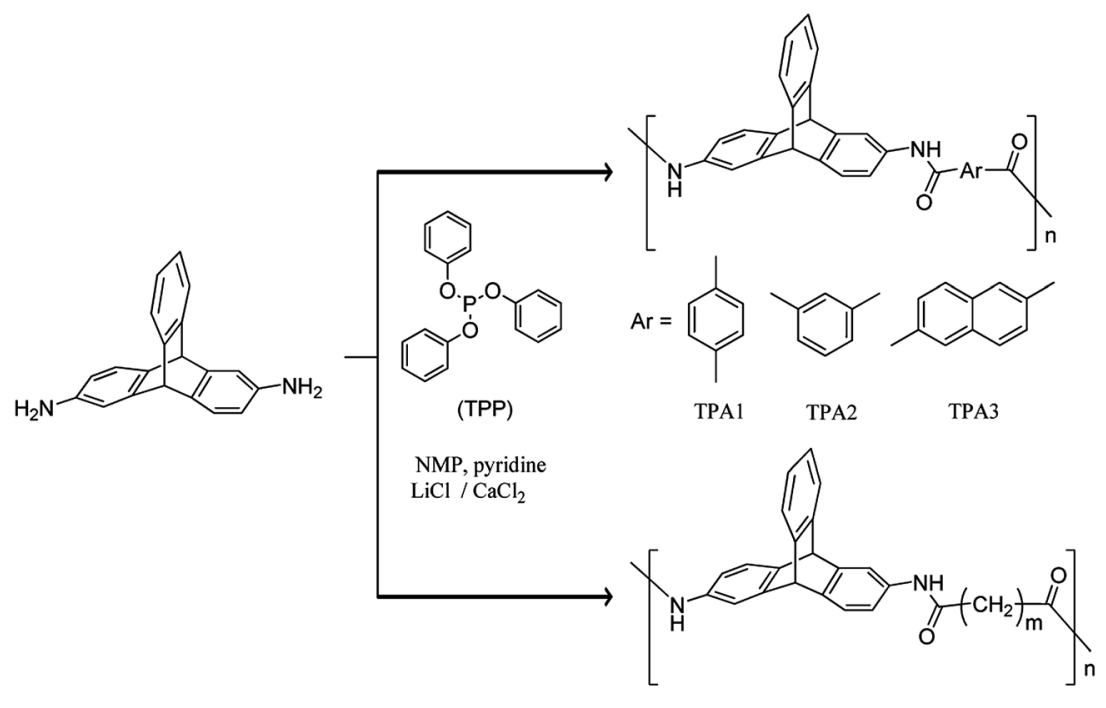

$m=4$ (TPA4), 8 (TPA5), 10 (TPA6).

Scheme 2 Synthesis of TPA1-TPA6.

Table 1 Reaction yield, molecular weight data, thermal analysis results and inherent viscosity of polyamides (TPA1-TPA6)

\begin{tabular}{|c|c|c|c|c|c|c|c|c|c|}
\hline Polymer & Yield (\%) & $M_{\mathrm{n}}{ }^{a}(\mathrm{Da})$ & $\mathrm{PDI}^{a}$ & $P_{\mathrm{n}}{ }^{b}$ & $\eta_{\text {inh }}^{c}\left(\mathrm{dL} \mathrm{g}^{-1}\right)$ & $T_{\mathrm{g}}{ }^{d}\left({ }^{\circ} \mathrm{C}\right)$ & $\begin{array}{l}T_{\mathrm{d}} \text { at } 10 \% \\
\text { weight } \operatorname{loss}^{e}\left({ }^{\circ} \mathrm{C}\right)\end{array}$ & Char weight ${ }^{f}(\%)$ & LOI \\
\hline TPA1 & 98 & $25.3 \mathrm{k}$ & 1.23 & 61 & 0.23 & $>300$ & 428 & 66.65 & 44.10 \\
\hline TPA3 & 99 & 33k & 1.35 & 71 & 0.51 & $>300$ & 488 & 71.29 & 46.02 \\
\hline TPA4 & 94 & $25.5 \mathrm{k}$ & 1.29 & 65 & 0.31 & $>300$ & 372 & 54.48 & 39.29 \\
\hline TPA5 & 98 & $24 \mathrm{k}$ & 1.23 & 54 & 0.18 & $>300$ & 383 & 40.22 & 33.58 \\
\hline
\end{tabular}

${ }^{a}$ Number average molecular weight $\left(M_{\mathrm{n}}\right)$ and polydispersity index (PDI, $M_{\mathrm{w}} / M_{\mathrm{n}}$ ) were determined using polystyrene standard and DMF (with $0.5 \%$ $\mathrm{LiBr}$ as additive) as an eluent. ${ }^{b}$ Degree of polymerization $\left(P_{\mathrm{n}}\right)$ determined from $M_{\mathrm{n}} \cdot{ }^{c}$ Measured in DMF at a concentration of $0.5 \mathrm{~g} \mathrm{dL} \mathrm{d}^{-1}$ at $25{ }^{\circ} \mathrm{C}$. ${ }^{d}$ Samples were heated from $-50{ }^{\circ} \mathrm{C}$ to $300^{\circ} \mathrm{C}$ at a scan rate $10^{\circ} \mathrm{C} \mathrm{min}^{-1}$ under $\mathrm{N}_{2}$ at a flow rate $20 \mathrm{~mL} \mathrm{~min}^{-1}$. ${ }^{e}$ Samples were heated from $50{ }^{\circ} \mathrm{C}$ to $800{ }^{\circ} \mathrm{C}$ at a scan rate $10{ }^{\circ} \mathrm{C}$ min $^{-1}$ under $\mathrm{N}_{2}$ at a flow rate $100 \mathrm{~mL} \mathrm{~min}^{-1}, T_{\mathrm{d}}$ were measured at $10 \%$ weight loss. ${ }^{f}$ Char weight of polyamides are calculated at $800{ }^{\circ} \mathrm{C}$.

FTIR spectroscopy was also used to confirm structural features of the polyamides. FTIR spectrum of TPA3 and TPA6 are shown as representative examples of a wholly aromatic polyamide and a semi-aromatic polyamide respectively in Fig. 2 . FTIR spectrum of TPA3 has a broad band at $3280 \mathrm{~cm}^{-1}$

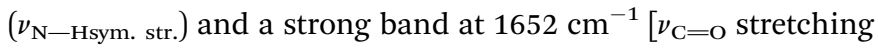
(amide I) of amide group]. Similarly in case of TPA6, the bands at $3292 \mathrm{~cm}^{-1}$ and $1662 \mathrm{~cm}^{-1}$ are assigned to $\nu_{\mathrm{N}-\mathrm{H}}$ symmetrical stretching and $\nu_{\mathrm{C}=\mathrm{O}}$ stretching vibration of amide group respectively. In general, absence of symmetrical stretching band at $3400-3500 \mathrm{~cm}^{-1}$ (characteristics peak of primary amine) in the FTIR spectra of all polyamides reported herein confirm polycondensation reaction. FTIR spectra of other polyamides (TPA1, TPA2, TPA4 and TPA5) also exhibit strong peak for $\nu_{\mathrm{C}=\mathrm{O}}$ stretching and broad band for $\nu_{\mathrm{N}-\mathrm{H}}$ symmetrical stretching in the range $1657-1663 \mathrm{~cm}^{-1}$ and $3285-3302 \mathrm{~cm}^{-1}$ respectively.

\section{Properties of polyamides}

Previously, it has been shown that triptycene based polyamides are soluble in polar solvents (such as NMP, HMPA, DMAc, DMF, DMSO, $m$-cresol, THF, cyclohexanone or pyridine) at room temperature or upon heating. In the present study, polyamides (TPA1-TPA6) are no exception, since they have excellent solubilities in highly polar aprotic solvent such as NMP, DMAc, DMF, and DMSO at room temperature. However unlike the previously reported polyamides containing triptycene motifs, polymers (TPA1-TPA6) are also readily soluble in moderately polar solvents such as Pyridine at room temperature (see ESI $\dagger$ ). The presence of bulky triptycene units in the polymer backbone inhibits efficient packing of the polymer chains and decreases interchain interactions, thereby contributing to improved solubilities.

\section{Thermal properties}

Thermal properties of the polyamides were investigated by thermogravimetric analysis (TGA) and differential scanning 

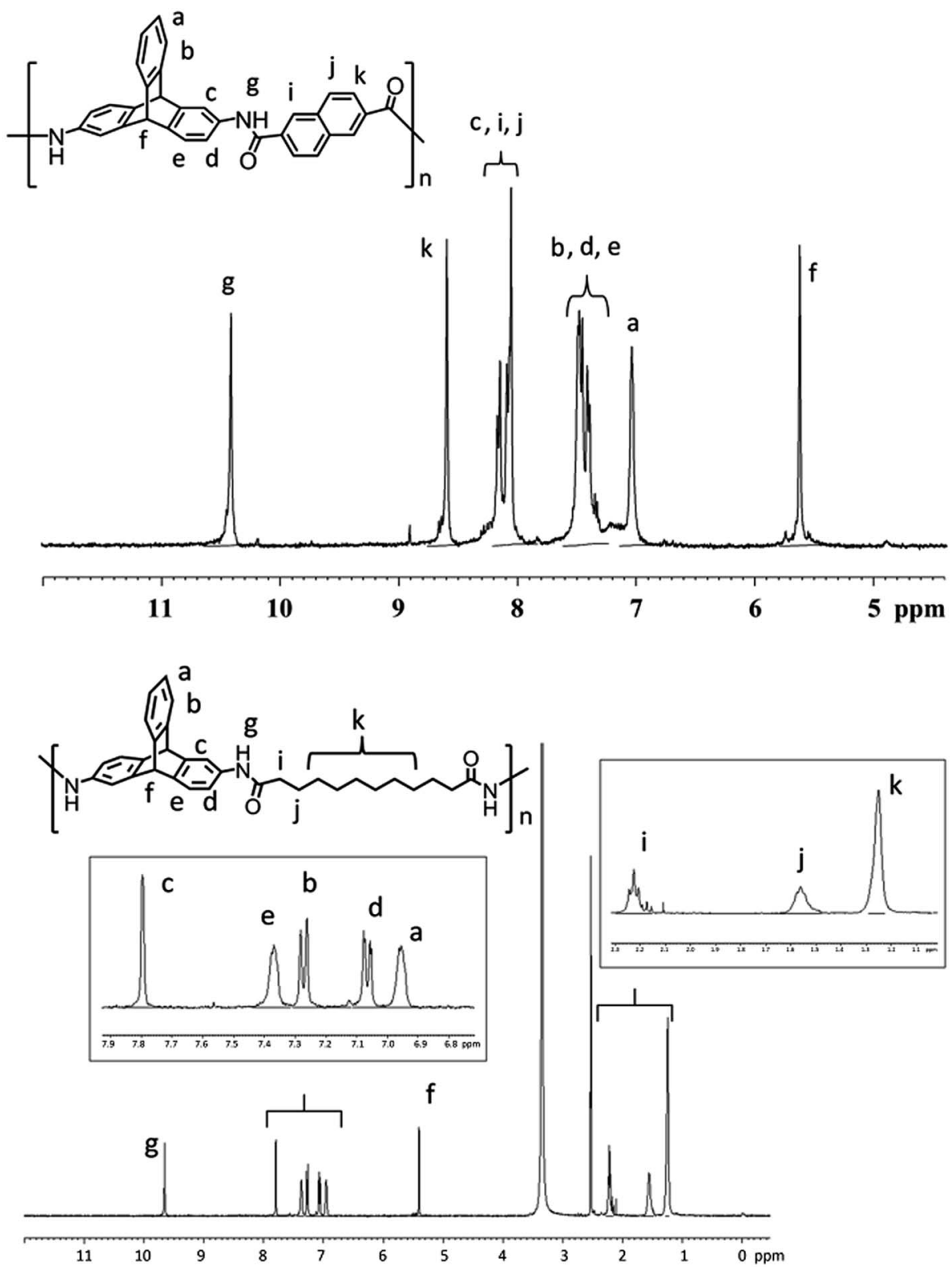

Fig. $1{ }^{1} \mathrm{H}$ NMR spectra of TPA3 (Top) and TPA6 (bottom) recorded at ambient temperature in DMSO- $\mathrm{d}_{6}$ solvent. Insets: expansions of aromatic and aliphatic region of TPA6.

calorimetry (DSC). TGA has been performed under a nitrogen atmosphere (heating rate: $10{ }^{\circ} \mathrm{C} \mathrm{min}^{-1}$ ). Data obtained from these studies are tabulated in Table 1 . TGA analysis curves and $T_{\mathrm{d}}$ values clearly indicate that triptycene polyamides containing aliphatic chains are thermally less stable than the wholly aromatic triptycene polyamides (Fig. 3). This is also evident from the char yields of the polymers at $800{ }^{\circ} \mathrm{C}$. In the case of wholly aromatic triptycene polyamides, the char yield is greater than $66 \%$, while in case of the polyamides with flexible alkyl chains, the char yields are relatively low. This suggests that incorporation of flexible aliphatic chains in the polymer backbone results in deterioration in their thermal stability. Wholly aromatic TPAs reported herein have comparable thermal stability with other previously reported triptycene polyamides.
Based on the van Krevelen and Hoftyzer equation (eqn (1)), ${ }^{66,67}$ limiting oxygen index (LOI) of a given polymer can be calculated from its respective char yield.

$$
\mathrm{LOI}=17.5+0.4 \mathrm{CR}
$$

$(\mathrm{CR}=$ char yield $)$.

LOI values are often used to gauge flammability of polymers or their tendency to sustain flame. Materials with LOI value greater than 28 are classified as "self-extinguishing". ${ }^{68}$ In case of the triptycene polyamides reported herein, LOI values are greater than 44 for wholly aromatic polymers (TPA1-3), where as for the semiaromatic ones (TPA4-6), LOI values are greater than 33. Thus, based on LOI values, it can be concluded that wholly 

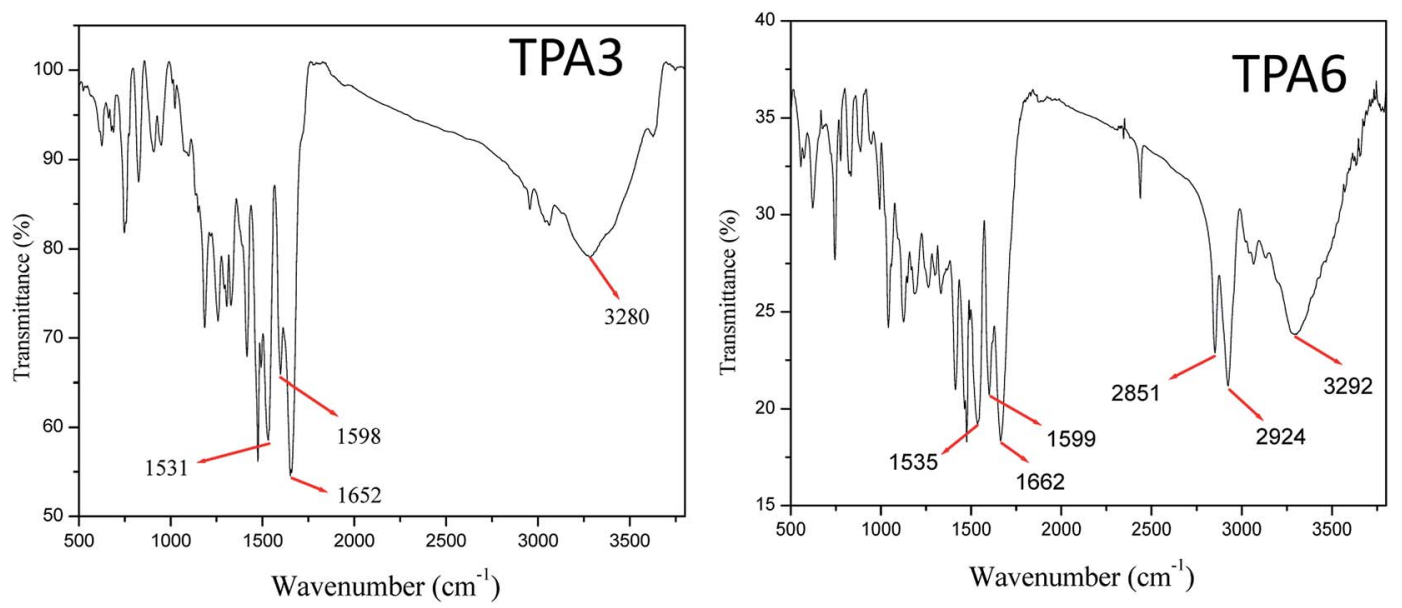

Fig. 2 FTIR spectra of TPA3 (left) and TPA6 (right) recorded at ambient temperature.

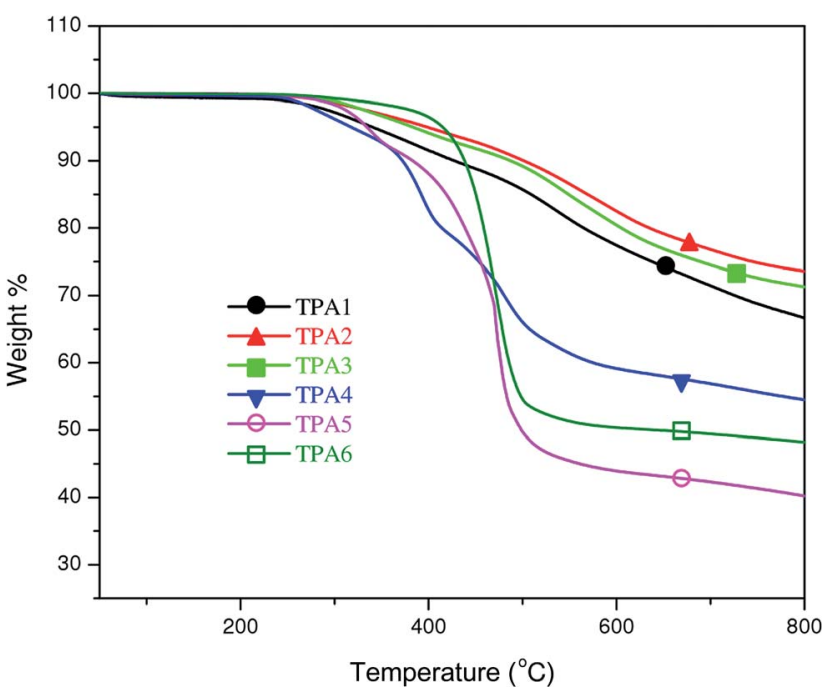

Fig. 3 TGA traces of TPA1-TPA6 under $\mathrm{N}_{2}$ at a scan rate $10^{\circ} \mathrm{C} \mathrm{min}^{-1}$.

aromatic polyamides are better fire-retardants than the semiaromatic analogues, albeit both class of triptycene polyamides may be categorized as "self-extinguishing" polymers.

The resulting polymers have high solubility (in common organic solvents) and high thermal stability. These properties are usually observed in case of cardo-polymers (i.e. polymer containing cardo $^{69}$ groups such as xanthenes ${ }^{70}$ ). Although TPAs reported herein don't contain cardo-groups (lateral ring connected to the main macromolecular backbone by a quaternary carbon atom), these polymers show cardo specific properties such as have organosolubility and high thermal stability. These cardo-specific properties are attributed to the presence of rigid triptycene motifs.

From DSC analysis of TPAs, no glass transition temperature $\left(T_{\mathrm{g}}\right)$ was observed upto $300{ }^{\circ} \mathrm{C}(\mathrm{ESI} \dagger)$.

\section{$\mathrm{X}$-ray diffraction of the polymers}

The wide angle X-ray diffraction (WAXD) patterns for polyamides (TPA1-TPA6) are shown in Fig. 4. Few sharp reflexes are observed in WAXD pattern only in case of TPA6 (\% crystallinity $=2.78$ ). In general, the broad spectra of TPAs suggest amorphous nature of these polyamides. This is due to the triptycene units in polymer backbone that reduce the extent of close packing and hence loss of crystallinity.

\section{Optical properties}

UV-vis spectra of the polyamides have been recorded in DMF (Fig. 5). TPAs containing aliphatic chain (TPA4-TPA6) show absorption band having maxima at $258 \mathrm{~nm}$ with a shoulder near $296 \mathrm{~nm}$. The differences in length of the aliphatic chains do not have any marked change in the nature of the absorption spectra of these polyamides. The peaks are assigned to $\pi-\pi^{*}$ transitions in the aromatic rings of triptycene. In case of wholly aromatic TPAs (TPA1-TPA3), the highest intensity absorption bands have maxima beyond $280 \mathrm{~nm}$. In case of TPA3, the value of $\lambda_{\max }$ is highest among all triptycene polyamides reported herein, and this is attributed to the $\mathrm{n}-\pi^{*}$ transitions in the carbonyl groups present in conjugation with the naphthalene ring present in the polymer backbone.

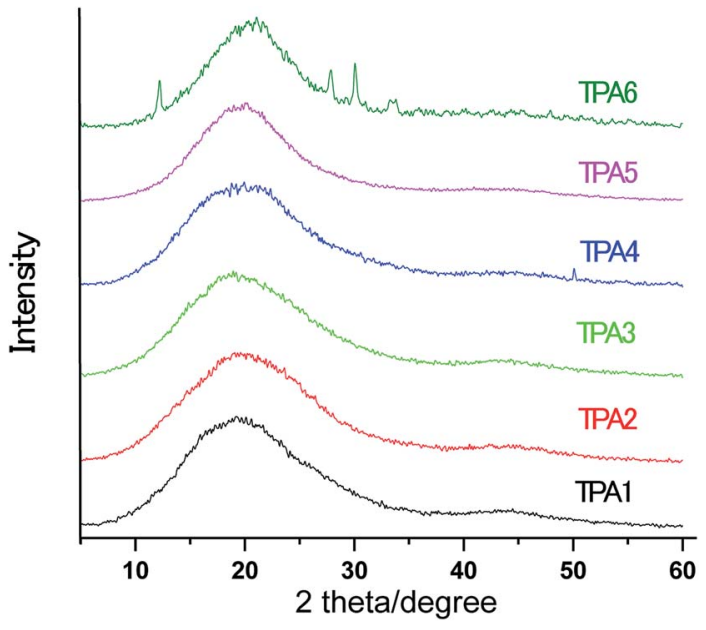

Fig. 4 WAXD pattern of the TPA1-TPA6 recorded at a scan rate $3^{\circ}$ $\min ^{-1}$ at ambient temperature. 


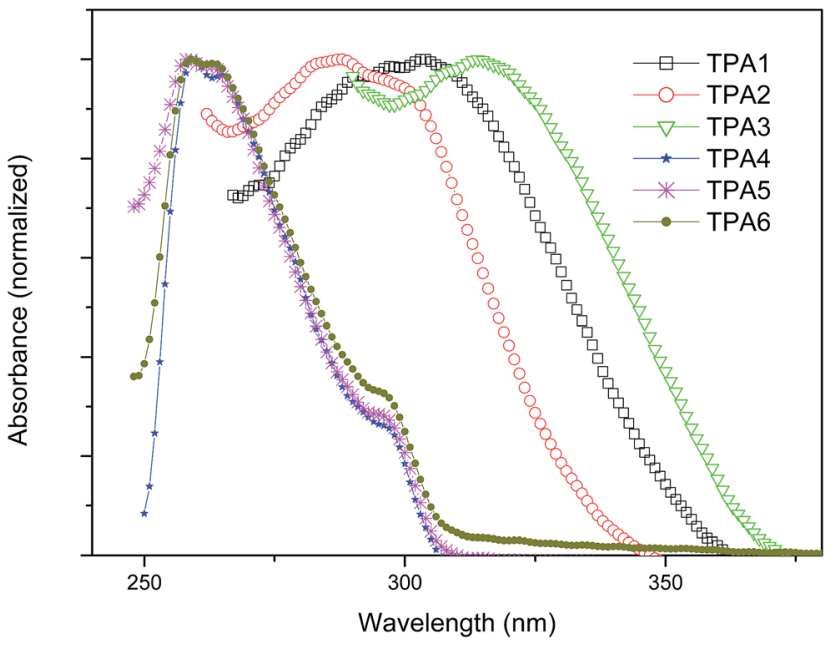

Fig. 5 Normalized UV-vis spectra of polyamides (TPA1-TPA6) in DMF at $298 \mathrm{~K}$.

\section{Hydrogen bonding behavior of TPAs}

Study of hydrogen bonding is important in case of polyamides as these interactions affect the thermal and mechanical properties of a given polymer. In general, strength of polyamides is often attributed to high degree of hydrogen bonding (interchain as well as intrachain). It is expected that presence of large number of bulky triptycene motifs in polymer backbone will restrict close packing of polymer chains and consequently interchain interactions via hydrogen bonding interactions will be minimized.

FTIR spectroscopy can be conveniently used as a tool to study the extent of hydrogen bonding interactions in these triptycene based polyamides which arise due to interactions between the oxygen atom of the carbonyl (H-bond acceptor) and the $\mathrm{N}-\mathrm{H}$ (H-bond donor) groups. It is expected that hydrogen bonded carbonyl will exhibit a $\mathrm{C}=\mathrm{O}$ stretching vibration band at a lower wavenumber than that due to the non-hydrogen bonded carbonyl group. This is due to the reduced electron density in the carbonyl group and consequential bond weakening upon its involvement in hydrogen bonding. ${ }^{59}$ In the FTIR spectra of the triptycene based polyamides reported herein, the stretching vibration bands of the carbonyl groups have split into two peaks. In case of each polyamide (TPA1-TPA6), the lower wavenumber band corresponds to hydrogen bonded carbonyl groups and the higher wavenumber band is attributed to nonhydrogen bonded carbonyl groups. This clearly indicates that in general, the hydrogen bonds are disrupted to a considerable extent by the presence of bulky triptycene unit. By comparing the relative intensity of the two aforementioned peaks, the strength of the hydrogen bonding interactions can be predicted.

As shown in Fig. 6, in case of wholly aromatic polyamides (TPA1-TPA3), wherein triptycene motifs are bridged by rigid aromatic spacers, the relative intensity of the hydrogen bonded carbonyl peak is less than that in case of the semi-aromatic polyamides (TPA4-TPA6), wherein triptycene motifs are bridged by aliphatic spacers. This suggests that in addition to the bulky triptycene units, the relatively rigid aromatic bridges also contribute to packing inefficiency, which is clearly reflected by the presence of a relatively less intense hydrogen bonded carbonyl peak.

The presence of more flexible aliphatic chains (in case of TPA4-TPA6) is a probable reason for a higher degree of hydrogen bonding interaction in semi-aromatic polymers in comparison to their wholly aromatic counterparts. The conclusion, that TPA4-TPA6 exhibit higher degree of hydrogen bonding interactions, is also supported by observing the nature of the $\mathrm{N}-\mathrm{H}$ peak in these polymers. It is known that the narrower $\nu_{\mathrm{N}-\mathrm{H}}$ stretching vibration peak, correspond to a higher degree of hydrogen bonding. ${ }^{59}$ As shown in Fig. 7, triptycene based polyamides with bridging aromatic moieties show a relatively broader $\nu_{\mathrm{N}-\mathrm{H}}$ stretching vibration peak in comparison
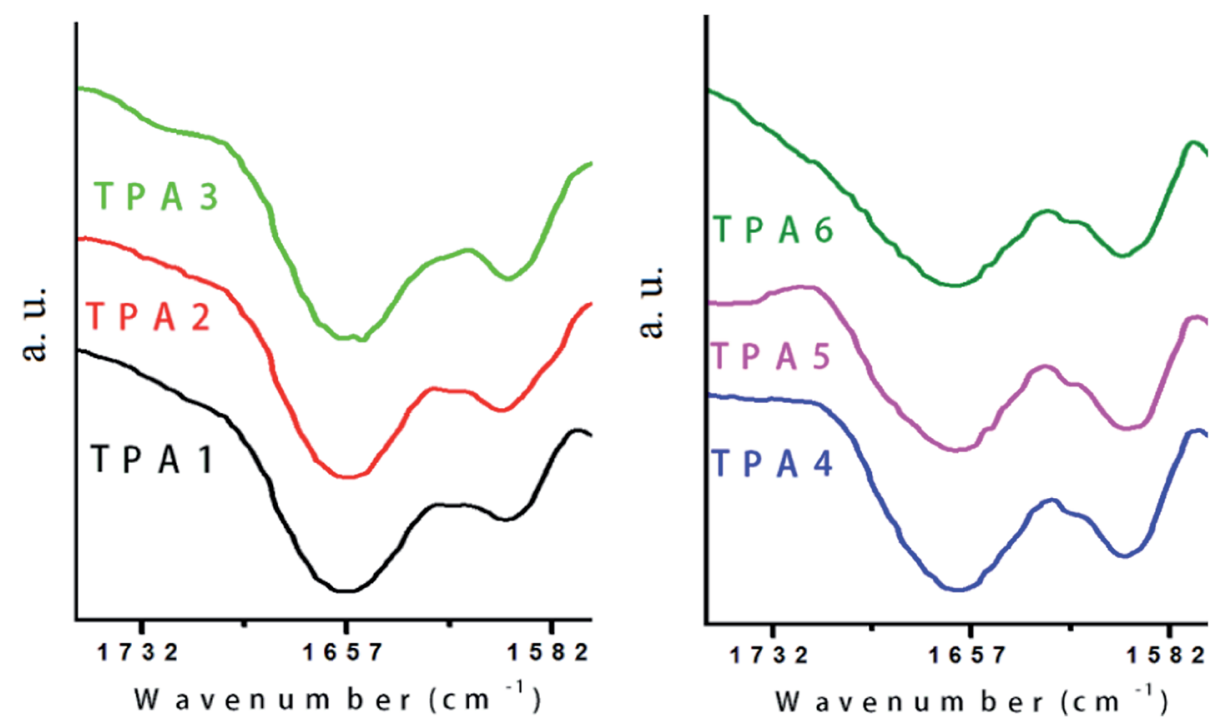

Fig. 6 FTIR spectra in the carbonyl region of TPA1-TPA6 recorded at $298 \mathrm{~K}$. 

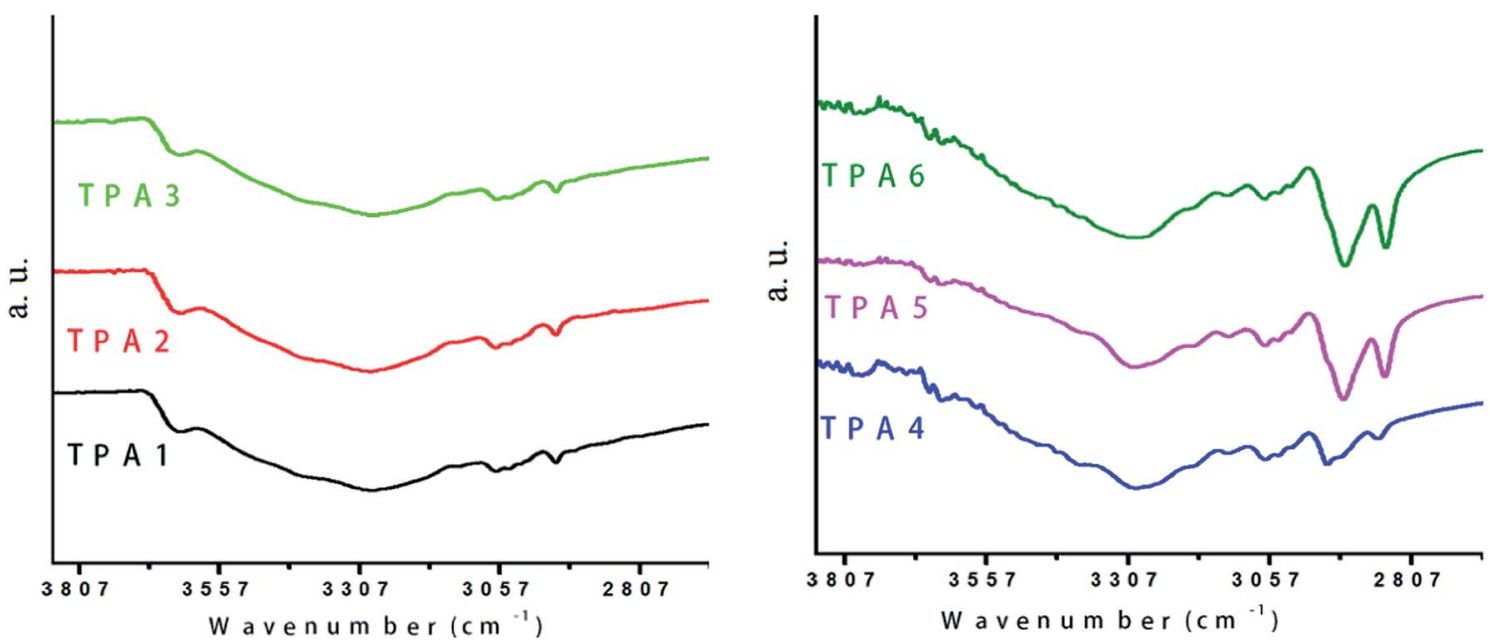

Fig. 7 FTIR spectra in the $\mathrm{N}-\mathrm{H}$ region of TPA1-TPA6 recorded at $298 \mathrm{~K}$.

to the polyamides (TPA4-TPA6) with more flexible aliphatic hydrocarbon chains.

\section{Surface morphology characterization}

Morphology of powder polyamide samples were studied by field emission scanning electron microscopy (FE-SEM) analysis. In each case, a droplet of the suspended polyamide in hexane $(0.1$ $\mathrm{wt} \%)$ was placed on a carbon tape and carefully dried under vacuum prior to FE-SEM analysis. The dried sample was then coated with platinum on an ion sputter coater and the images were taken at various levels of magnifications. Scanning electron micrographs depicting the general morphological features for TPAs are shown in Fig. 8. The Field emission SEM (FE-SEM) images, in case of wholly aromatic polyamides (TPA1-TPA3), indicate the presence of globular particles with diameter ranging from 50 to $550 \mathrm{~nm}$. TPA1 and TPA2 have similar morphological features and this is due to the similar bridging aromatic group. In TPA3, the naphthyl group replaces the phenyl groups present in TPA1 and TPA2. This probably results in greater aggregation of the globular particles in TPA3. To calculate the particle size distribution of polyamides TPA1-TPA3, five different areas were randomly selected at higher magnification and dimension of each particle measured. The particle size distribution was subsequently plotted in the form of histograms. In each case, the particle size distribution (from SEM images) fitted well with a Gaussian curve as shown in Fig. 9. The average particle size was obtained from the fitted data. ${ }^{71,72}$ The average particle size thus determined in case of polyamides TPA1 and TPA2 are $185 \mathrm{~nm}$ and $166 \mathrm{~nm}$ respectively. In case of TPA3, the average particle size was relatively
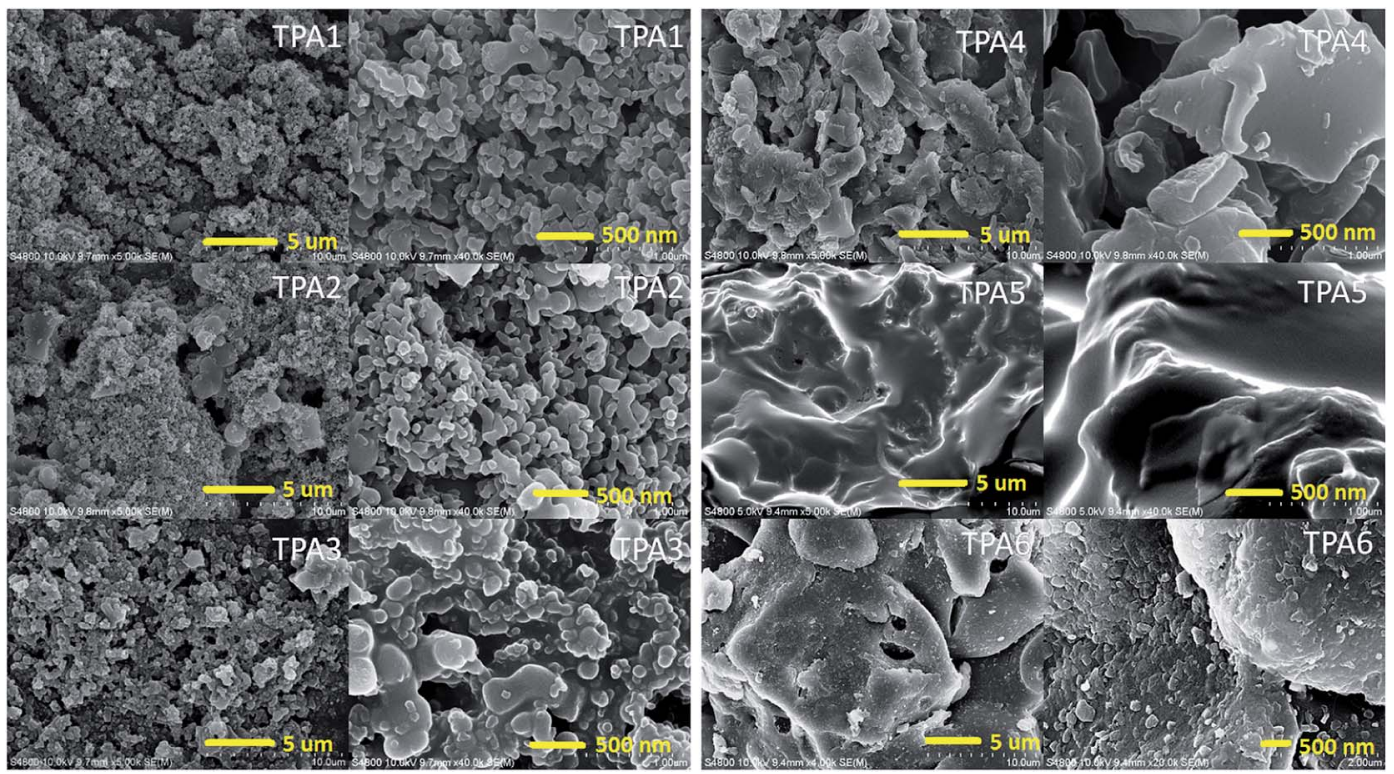

Fig. 8 FE-SEM micrograph of TPA1-TPA6 at two different magnifications. 

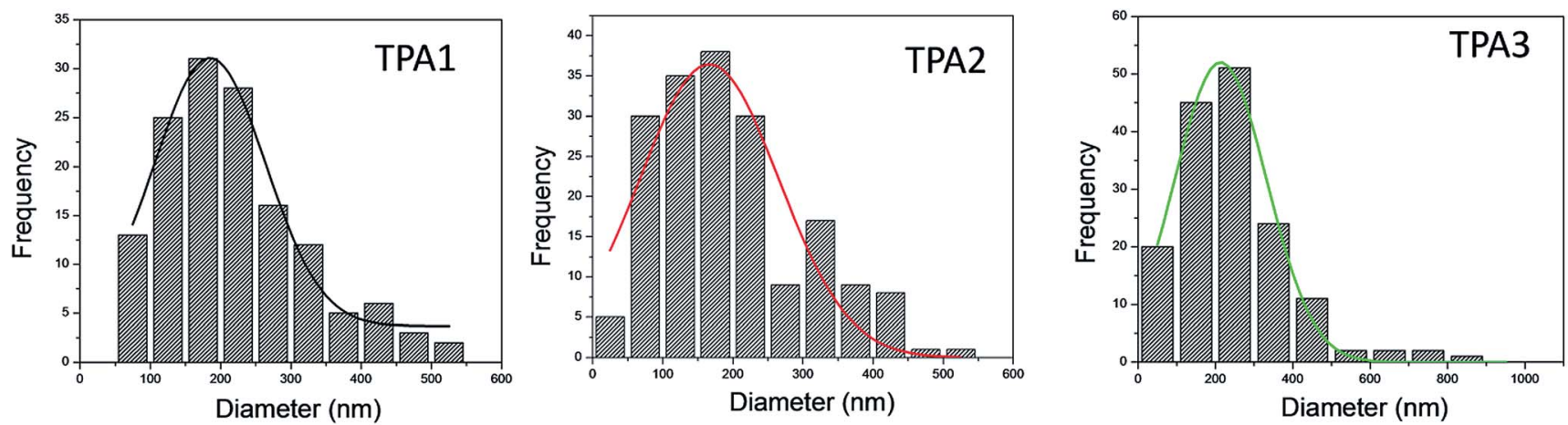

Fig. 9 Particle size distribution histogram of TPA1-TPA3 (left to right), fitted with a Gaussian curve.

higher (213 nm), and this may be attribute to greater extent of aggregation in TPA3 when compared with polyamides TPA1 and TPA2.

Further from SEM images, it can be concluded that replacement of rigid aromatic bridging groups by relatively more flexible aliphatic chains results in considerable change in the surface morphologies. In case of semi-aromatic triptycene polyamides (TPA4-TPA6), SEM images revealed more aggregation as evident from plate-like morphologies. ${ }^{73,74}$ FTIR spectroscopy results clearly indicate that the degree of hydrogen bonding is greater in the semi-aromatic polyamides in comparison to the wholly aromatic triptycene polyamides. This greater extent of hydrogen bonding as well as the presence of favorable hydrophobic interactions between the aliphatic chains attribute to the observed change of surface morphologies in TPAs containing aliphatic bridges, thus leading to higher aggregation.

From FTIR and FE-SEM analyses, it is clearly observed that the interchain interactions of triptycene based polyamides vary extensively depending on the flexibility of polymer backbone as well as nature of the spacer. This parameter also significantly affects the surface morphology of the resulting polymer. In general, with increasing flexibility of the spacer, there is a considerable enhancement in the interchain interactions (as evident from FTIR) which leads to more aggregated plate like morphologies (as evident from FE-SEM). On the other hand for more rigid structure, there is an inhibition in interchain interactions which leads to the formation of less aggregated globular particles. This structure-property relationship may be employed to obtain different morphological characteristics as per requirement.

\section{Conclusions}

In conclusion, we report two series of triptycene based polyamides (TPAs) that were prepared utilizing DAT and various aromatic or aliphatic dicarboxylates via Yamazaki-Higashi phosphorylation polyamidation reaction in high yields $(\geq 89 \%)$. In general, incorporation of rigid triptycene motifs in polyamide chains render the TPAs organosoluble (even in less polar solvents such as pyridine) and non-crystalline in nature. Irrespective of the bridging dicarboxylates used, solution viscosities studies of TPAs (0.5 $\mathrm{g} \mathrm{dL}^{-1}$ polymer concentration in DMF) show extremely low viscosities $\left(0.18-0.51 \mathrm{dL} \mathrm{g}^{-1}\right)$. The polymers exhibit molecular weights $\left(M_{\mathrm{n}}\right)$ in the range between 25 and 33 $\mathrm{kDa}$, as evident from GPC analysis. The wholly aromatic TPAs (TPA1-TPA3) exhibit higher $T_{\mathrm{d}}$ (10\% weight loss temperature under nitrogen) in comparison to the semi-aromatic TPAs (TPA4-TPA6). Wholly aromatic polyamides (TPA1-TPA3) exhibit significantly less hydrogen bonding than semi-aromatic polyamides (TPA4-TPA6) bearing flexible aliphatic segment. This is reflected in the morphological differences as observed in SEM images. The low inherent viscosities and organosoluble nature of the TPAs render facile solution processability of these thermally stable polymers. From an application viewpoint, based on the char yield and the corresponding LOI values, polyamides reported herein are "self-extinguishing" in nature and hence can be considered to as fire-retardant materials. In summary, TPAs reported herein can be considered as promising candidates for processable high temperature applications.

\section{Acknowledgements}

N.D. thanks the CSIR, Govt. of India, New Delhi [CSIR No. 02(0126)/13/EMR-II] and the Indian Institute of Technology Patna, for financial support. S.M. thanks UGC, New Delhi for a Research Fellowship. The authors also acknowledge SAIF-Panjab University for providing analytical facilities.

\section{Notes and references}

1 M. Yang, K. Cao, L. Sui, Y. Qi, J. Zhu, A. Waas, E. M. Arruda, J. Kieffer, M. D. Thouless and N. A. Kotov, ACS Nano, 2011, 9, 6945-6954.

2 K. Marchildon, Macromol. React. Eng., 2011, 5, 22-54.

3 M. Shadpour and D. J. Mohammad, J. Macromol. Sci., Part A: Pure Appl.Chem., 2011, 48, 644-679.

4 S. Banerjee and S. Maji, in High Performance Polymers and Engineering Plastics, ed. Vikas M., Scrivener publishing, Salem, 2011, pp. 111-166.

5 J. M. García, F. C. García, F. Serna and J. L. de la Peña, Prog. Polym. Sci., 2010, 35, 623-686.

6 M. Scholl, Z. Kadlecova and H.-A. Klok, Prog. Polym. Sci., 2009, 34, 24-61. 
7 M. Trigo-López, P. Estévez, N. San-José, A. GómezValdemoro, F. C. García, F. Serna, J. L. de la Peña and J. M. García, Recent Pat. Mater. Sci., 2009, 2, 190-208.

8 S. Zulfiqar, M. Ishaq and M. I. Sarwar, Adv. Polym. Technol., 2010, 29, 300-308.

9 H. R. Kricheldorf, S. Böhme and G. Schwarz, Macromolecules, 2001, 34, 8879-8885.

10 K. Ishihara, S. Ohara and H. Yamamoto, Macromolecules, 2000, 33, 3511-3513.

11 V. Rajendran and M. J. Nanjan, J. Polym. Sci., Part A: Polym. Chem., 1987, 25, 829-838.

12 S. Chidambaram and M. J. Nanjan, Makromol. Chem., 1983, 184, 2225-2230.

13 D.-J. Liaw, F.-C. Chang, M.-K. Leung, M.-Y. Chou and K. Muellen, Macromolecules, 2005, 38, 4024-4029.

14 M. Arpin and C. Strazielle, Polymer, 1977, 18, 591-598.

15 P. E. Cassidy, in Thermally Stable Polymers, Marcel Dekker, New York, 1980, ch. 4.

16 H. H. Yang, in Aromatic High-Strength Fibres, John Wiley, New York, 1989, pp. 66-289.

17 S.-R. Sheng, X.-L. Pei, Z.-Z. Huang, X.-L. Liu and C.-S. Song, Eur. Polym. J., 2009, 45, 230-236.

18 E. Charles and J. Carraher, Introduction to Polymer Chemistry, Taylor \& Francis, New York, 3rd edn, 2012.

19 D.-J. Liaw, B.-Y. Liaw, J.-R. Chen and C.-M. Yang, Macromolecules, 1999, 32, 6860-6863.

20 H. R. Kricheldorf and B. Schmidt, Macromolecules, 1992, 25, 5471-5476.

21 H. R. Kricheldorf and R. J. Burger, J. Polym. Sci., Part A: Polym. Chem., 1994, 32, 355-362.

22 D.-J. Liaw, in Macromolecular Nanostructured Materials, ed. Ueyama N. and Harada A., Kodansha \& Springer, Tokyo, 2004, Ch. 2.2, pp. 80-100.

23 Y.-C. Huang, K.-L. Wang, C.-H. Chang, Y.-A. Liao, D.-J. Liaw, K.-R. Lee and J.-Y. Lai, Macromolecules, 2013, 46, 7443-7450 and reference therein.

24 M.-D. Damaceanu, R.-D. Rusu, A. Nicolescu, M. Bruma and A. L. Rusanov, Polym. Int., 2011, 60, 1248-1258.

25 D.-J. Liaw, B.-Y. Liaw and C.-M. Yang, Macromolecules, 1999, 32, 7248-7250.

26 D.-J. Liaw and B.-Y. Liaw, Macromol. Chem. Phys., 1999, 200, 1326-1332.

27 D.-J. Liaw, B.-Y. Liaw and C. Y. Chung, Acta Polym., 1999, 50, 135-140.

28 D.-J. Liaw and B.-Y. Liaw, J. Polym. Sci., Part A: Polym. Chem., 1998, 36, 1069-1074.

29 D.-J. Liaw and B.-Y. Liaw, Macromol. Symp., 1997, 122, 343348.

30 I. K. Spiliopoulos, J. A. Mikroyannidis and G. M. Tsivgoulis, Macromolecules, 1998, 31, 522-529.

31 I. K. Spiliopoulos and J. A. Mikroyannidis, Macromolecules, 1998, 31, 1236-1245.

32 I. K. Spiliopoulos and J. A. Mikroyannidis, Macromolecules, 1996, 29, 5313-5319.

33 A. E. Lozano, J. de Abajo, J. G. de la Campa and J. Preston, J. Polym. Sci., Part A: Polym. Chem., 1995, 33, 1987-1994.
34 D.-J. Liaw, B.-Y. Liaw, J.-R. Chen and C.-M. Yang, Macromolecules, 1999, 32, 6860-6863.

35 M. Yamashita, M. A. Kakimoto and Y. Imai, J. Polym. Sci., Part A: Polym. Chem., 1993, 31, 1513-1518.

36 M. Lucas, P. Brock and J. L. Hedrich, J. Polym. Sci., Part A: Polym. Chem., 1993, 31, 2179-2185.

37 M. R. Bellomo, G. D. Pasquale, A. L. Rosa, A. Pollicino and G. Siracusa, Polymer, 1996, 37, 2877-2881.

38 D.-J. Liaw, B.-Y. Liaw and M. Y. Tsai, Polym. J., 1997, 29, 474477.

39 D.-J. Liaw and B.-Y. Liaw, J. Polym. Sci., Part A: Polym. Chem., 1998, 36, 1075-1080.

40 P. D. Bartlett, M. J. Ryan and S. G. Cohen, J. Am. Chem. Soc., 1942, 64, 2649-2653.

41 B. H. Klanderman and J. W. H. Faber, J. Polym. Sci., Polym. Chem. Ed., 1968, 6, 2955-2965.

42 C.-F. Chen and Y.-X. Ma, Iptycene Chemistry: from Synthesis to Applications, Springer-Verlag, Berlin, 2013.

43 P.-F. Li and C.-F. Chen, J. Org. Chem., 2012, 77, 9250-9259.

44 Y. Jiang and C.-F. Chen, Eur. J. Org. Chem., 2011, 32, 63776403.

45 C.-F. Chen, Chem. Commun., 2011, 47, 1674-1688.

46 J. H. Chong and M. MacLachlan, Chem. Soc. Rev., 2009, 38, 3301-3315.

47 T. M. Swager, Acc. Chem. Res., 2008, 41, 1181-1189.

48 L. Zhao, Z. Li and T. Wirth, Chem. Lett., 2010, 39, 658-667.

49 S. A. Sydlik, P. A. Delgado, S. Inomata, B. VanVeller, Y. Yang, T. M. Swager and K. B. Wagener, J. Polym. Sci., Part A: Polym. Chem., 2013, 51, 1695-1706.

50 B. VanVeller, D. Robinson and T. M. Swager, Angew. Chem., Int. Ed., 2012, 51, 1182-1186.

51 B. VanVeller, D. J. Schipper and T. M. Swager, J. Am. Chem. Soc., 2012, 134, 7282-7285.

52 C. Simocko, Y. Yang, T. M. Swager and K. B. Wagener, ACS Macro Lett., 2013, 2, 1061-1064.

53 C. Zhang, Y. Liu, B. Li, B. Tan, C.-F. Chen, H.-B. Xu and X.-L. Yang, ACS Macro Lett., 2012, 1, 190-193.

54 Z. Chen and T. M. Swager, Macromolecules, 2008, 41, 68806885.

55 A. D. Regno, A. Gonciaruk, L. Leay, M. Carta, M. Croad, R. Malpass-Evans, N. B. McKeown and F. R. Siperstein, Ind. Eng. Chem. Res., 2013, 52, 16939-16950.

56 T.-Y. Zhou, F. Lin, Z.-T. Li and X. Zhao, Macromolecules, 2013, 46, 7745-7752.

57 X. Zhu, C.-L. Do-Thanh, C. R. Murdock, K. M. Nelson, C. Tian, S. Brown, S. M. Mahurin, D. M. Jenkins, J. Hu, B. Zhao, H. Liu and S. Dai, ACS Macro Lett., 2013, 2, 660-663. 58 S.-H. Hsiao, H.-M. Wang, J.-S. Chou, W. Guo and T.-H. Tsai, J. Polym. Res., 2012, 19, 9902-9909.

59 Z. Chang, M. Zhang, A. G. Hudson, E. B. Orler, R. B. Moore, G. L. Wilkes and S. R. Turner, Polymer, 2013, 54, 6910-6917. 60 Y. Kasashima, T. Kaneda, G. Saito, F. Akutsu, K. Naruchi and M. Miura, Macromol. Chem. Phys., 1994, 195, 2693-2697.

61 S. Chakraborty, S. Mondal, Q. Li and N. Das, Tetrahedron Lett., 2013, 54, 1681-1685.

62 S. Mondal, S. Chakraborty, S. Bhowmick and N. Das, Macromolecules, 2013, 46, 6824-6831. 
63 J. Zhao, H. Xu, J. Fang and J. Yin, J. Appl. Polym. Sci., 2012, 126, 244-252.

64 N. Yamazaki, M. Matsumoto and F. Higashi, J. Polym. Sci., Polym. Chem. Ed., 1975, 13, 1373-1380.

65 S. A. Sydlik, Z. Chen and T. M. Swager, Macromolecules, 2011, 44, 976-980 and references therein.

66 D. W. Van Krevelen and P. J. Hoftyzer, Properties of polymers, Elsevier, Amsterdam, 3rd edn, 1976.

67 Z. Rafiee and L. Golriz, Polym. Eng. Sci., 2014, 54, 2252-2257.

68 A. R. Horrocks, M. Tune and D. Price, Text. Prog., 1988, 18(1-3), 1-186.
69 V. V. Korshak, S. V. Vinogradova and Y. S. Vygodski, J. Macromol. Sci., Rev. Macromol. Chem., 1974, 11, 45-142.

70 S.-R. Sheng, C.-X. Ma, J.-W. Jiang, Z.-Z. Huang and C.-S. Song, J. Appl. Polym. Sci., 2010, 116, 1650-1659.

71 N. Suzuki, M. B. Zakaria, Y.-D. Chiang, K. C.-W. Wu and Y. Yamauchi, Phys. Chem. Chem. Phys., 2012, 14, 7427-7432.

72 N. Baccile, D. Grosso and C. Sanchez, J. Mater. Chem., 2003, 13, 3011-3016.

73 M. Ago, T. Endo and K. Okajima, Polym. J., 2007, 39, 435-441. 74 C. V. Rajaram, S. D. Hudson and L. C. Chien, Polymer, 1998, 39, 5315-5319. 